\title{
Erratum to: Application of particle swarm optimisation in artificial neural network for the prediction of tool life
}

\author{
U. Natarajan ${ }^{1} \cdot$ R. Saravanan ${ }^{2} \cdot$ V. M. Periasamy ${ }^{1}$
}

Published online: 10 February 2017

(C) Springer-Verlag London 2017

Erratum to: Int J Adv Manuf Technol (2006) 28: 1084- 1088

DOI 10.1007/s00170-004-2460-5

This article has been updated at some points and was published as a new publication under DOI 10.1007/s00170-0050252-1. This article will no longer be indexed and all current citations of this article will be transferred to the new publication.

The editors wish to note that the double publication was caused by an honest mistake. The editors apologize for any inconvenience this might have causes.

The online version of the original article can be found at http://dx.doi.org/ 10.1007/s00170-004-2460-5.

U. Natarajan

nattu69@rediffmail.com

1 Department of Mechanical Engineering, A.C. College of Engineering and Technology, Karaikudi, Tamil Nadu, India

2 Department of Mechanical Engineering, Kumaraguru College of Technology, Coimbatore, Tamil Nadu, India 